\title{
A Modified Jaslow-Transforaminal Lumbar Interbody Fusion for the Treatment of Isthmic Spondylolisthesis
}

\author{
ChaoJiang YU ${ }^{1}$, Xiao GAO ${ }^{1}$, Kai HUANG ${ }^{1}$, BuQing CHANG ${ }^{1}$, Hu FENG ${ }^{1}$, Jie ZHAO² \\ ${ }^{1}$ The Affiliated Hospital of Xuzhou Medical University, Department of Orthopedics, Xuzhou, China \\ ${ }^{2}$ Ninth People's Hospital, Shanghai Jiaotong University, Department of Orthopedics, Shanghai, China
}

\section{ABSTRACT}

AIM: To describe a modified Jaslow-transforaminal lumbar interbody fusion (TLIF) technique for the treatment of single-level, isthmic spondylolisthesis (IS).

MATERIAL and METHODS: Between April 2011 and September 2012, 32 patients with IS undergoing a modified Jaslow-TLIF were retrospectively reviewed. The intervertebral space height $(\mathrm{IH})$, vertebral slippage ratio, lordotic angles of the treated segments $(\mathrm{SA})$ and lumbar lordotic angles (LA) were measured and the scores by Visual Analogue Scale (VAS), Oswestry Disability Index (ODI) and Japanese Orthopaedic Association (JOA) were recorded.

RESULTS: An average follow-up duration of over 2 years was available. The average slippage percentage was $17.8 \pm 4.3 \%$ preoperatively, $5.3 \pm 2.4 \%$ postoperatively, and $5.4 \pm 2.5 \%$ at the last follow-up. The average IH was $7.7 \pm 1.9 \mathrm{~mm}$ preoperatively, $10.3 \pm 1.6 \mathrm{~mm}$ postoperatively, and $10.2 \pm 1.5 \mathrm{~mm}$ at the final follow-up. The average SA and LA were, respectively, $11.7 \pm 5.8^{\circ}$ and $49.1 \pm 13.9^{\circ}$ preoperatively, $13.5 \pm 5.7^{\circ}$ and $48.3 \pm 9.4^{\circ}$ postoperatively, and $13.2 \pm 5.3^{\circ}$ and $47.7 \pm 8.8^{\circ}$ at the last follow-up. The mean VAS was ameliorated from $7.7 \pm 0.6$ to $2.4 \pm 0.5$, ODI from $49.6 \pm 1.6 \%$ to $10.5 \pm 1.3 \%$, and JOA from $10.8 \pm 1.3$ to $26.6 \pm 1.0$, at the last follow-up. All patients had clinical and radiographic evidence of solid fusion without any need for revision.

CONCLUSION: The modified Jaslow-TLIF technique for the treatment of IS was advantageous for greater safety and efficacy.

KEYWORDS: Insert-and-rotate technique, Isthmic spondylolisthesis, Modified Jaslow technique, Transforaminal lumbar interbody fusion

\section{INTRODUCTION}

$\mathrm{I}$ sthmic spondylolisthesis (IS) is a common cause of low back pain and leg pain, for which surgery is the optimum Loption in the case of conservative therapy failure or aggravated disease as well as progressive neurological deficits $(9,12)$. Surgery for IS involves neurological decompression and sagittal spinal balance reconstruction, with reversal of the lumbosacral deformity achieved by reduction maneuvers. A number of surgical techniques can reportedly achieve reduction of lumbar IS $(10,15,22,24,27,36,37)$. The insertand-rotate posterior lumbar interbody fusion (PLIF) technique, which employed autogenous spinous process, was first described by Jaslow in 1946 (16). Sears (36) first reported the application of this technique in the treatment of IS, with satisfactory clinical outcomes. Thereafter, a modified PLIF technique to transforaminal lumbar interbody fusion (TLIF) technique, which has been applied as an alternative technique for surgical treatment of lumbar degenerative diseases $(13,44)$.

However, there is a paucity of reports on the outcomes of the insert and-rotate TLIF technique for the treatment of IS. In addition, no rigid criterion with respect to the distraction of interbody space is available, and most of the de facto operations could only be performed by the most experienced orthopedists, which greatly hampers the generalization of this 
technique. Recently, we modified the Jaslow technique to reduce the slippage of vertebrae combined with TLIF in the surgery for IS. We aimed to investigate the efficacy and safety of this reduction technique in IS in adults.

\section{MATERIAL and METHODS}

\section{Patients}

We retrospectively reviewed data from 32 selected patients, who had been surgically treated for IS in our hospital between April 2011 and September 2012. The inclusion criteria were as follows:

(1) IS of grade I or II

(2) Persistent or recurrent low back pain or leg pain lasting at least 6 months before operation with no benefits from conservative treatment over 3 months.

We excluded patients with osteoporosis, diabetes mellitus, symptomatic vascular diseases, active infection, tumor, IS of Grade II or greater, or clinical data deficiency. The protocol was approved by the Institutional Ethics Review Board and conducted in accordance with the provisions of the Declaration of Helsinki, with written informed consents provided by all the patients or their legal representatives.

\section{Clinical and Radiological Evaluation}

Clinical status of each patient was evaluated with the Visual Analogue Scale (VAS), Oswestry Disability Index (ODI) and Japanese Orthopedic Association (JOA) preoperatively and at the last follow-up. Functional improvement was expressed as the recovery rate by JOA (30). In addition, surgery duration, intra-operative blood loss and perioperative complications were also recorded. Subjective satisfaction outcomes were evaluated with a five-score scale (excellent, good, fair, unchanged, worse) (7). Radiologic assessments were performed with the assistance of lateral plain radiographs preoperatively, postoperatively and at the last follow-up. The intervertebral space height $(\mathrm{IH})$, the ratio of vertebral slippage, lordotic angles of the treated segments (SA) and lumbar lordosis angles (LA) were assessed using plain lateral radiographs prior and subsequent to surgery, and at the last follow-up (Figure 1). Additionally, osseous fusion was confirmed by the following criteria (8):

(1) The presence of continuous trabeculation and bone bridging between cage and vertebral endplates shown by lateral X-ray photography.

(2) The absence of a radiolucent line between the graft and endplates.

(3) The absence of angular motion of greater than $5^{\circ}$ and anteroposterior motion of over $3 \mathrm{~mm}$ at dynamic lateral lumbar radiograms at the fused levels.

\section{Surgical Technique}

Under general anesthesia, the patient was placed in a prone position on the Wilson frame. With bilateral vertebral lamina and articular process exposed, pedicle screws were placed. Subsequent to the floating total laminectomy and neuroradicular decompression, a preflexed short segmental rod was applied to stabilize the unilateral pedicle screw, with the upper screw nut semi-mobile and the hypogynous screw nut fastened to the fixed jaw (Figure 2A). A trial spacer of the smallest size was then advanced into intervertebral space and rotated by 90 degrees (Figure 2B, C), followed by the fixation of upper screw nut to achieve intervertebral distraction (Figure 2D). With the pedicle screw instrumentation locked in place, the nucleus pulposus and cartilaginous end plates were removed (Figure 2E). With the upper screw nut released (Figure 2F), the intervertebal space was expanded with another spacer of a larger size (Figure $2 \mathrm{G}$ ).

The criteria of intervertebral distraction were as follows:

(1) Normal tonus of the anterior wall of annulus fibrosus and anterior longitudinal ligament.

(2) The height of segment concerned approximate to the mean height of superior and inferior intervertebral space by intraoperative radiography.

With the intervertebral space height restored, the annular ligamentotaxis gradually developed some tension, which could partially promote the reduction of the slipped vertebrae (Figure $2 \mathrm{H})$. In addition, complete decompression of the intervertebral disc also contributed to vertebral reduction. Cancellous bone from lamina and facet joints was introduced into the disc space and a parallelogram-shaped cage implanted within. Preflexed connecting rods were bilaterally fixed at pedicle screw with nuts. Finally, with neuroradicular relaxation achieved, a lumbar transverse connector was placed.

\section{Statistical Analysis}

Data were expressed as mean $\pm S D$ and all statistical analyses were conducted using SPSS 18.0 software, with $\mathrm{p}<0.05$ considered statistically significant. The results were statistically analyzed using a two-tailed paired Student $t$ test.

\section{RESULTS}

\section{Patient Demographics}

There were 32 patients ( 28 females and 4 males) with a mean age of $52.6 \pm 9.6 \mathrm{yrs}$ (range, 34 to $80 \mathrm{yrs}$ ) at the time of the surgery. The location of slippage was L4-L5 in 20 patients (62.5\%) and L5-S1 in 12 patients (37.5\%). The median duration of follow-up was $33.0 \pm 2.8$ months (range, 27 to 38 months). The mean duration of operation was $152 \pm 10$ minutes (range: 140 to 170 minutes), and the average volume of estimated intraoperative blood loss was $534 \pm 106 \mathrm{ml}$ (range, 410 to 780 $\mathrm{ml}$ ). One patient had the complication of cerebrospinal fluid leakage and was cured in 7 days. There were no postoperative neurologic complications, wound infections or fracture of rod and nail and subsidence of the cages.

\section{Radiological Outcomes}

The average ratio of vertebral slippage was significantly lower postoperatively than was preoperatively $(17.8 \pm 4.3 \%$ vs. $5.3 \pm 2.4 \%, p<0.001)$. The IH was significantly increased 


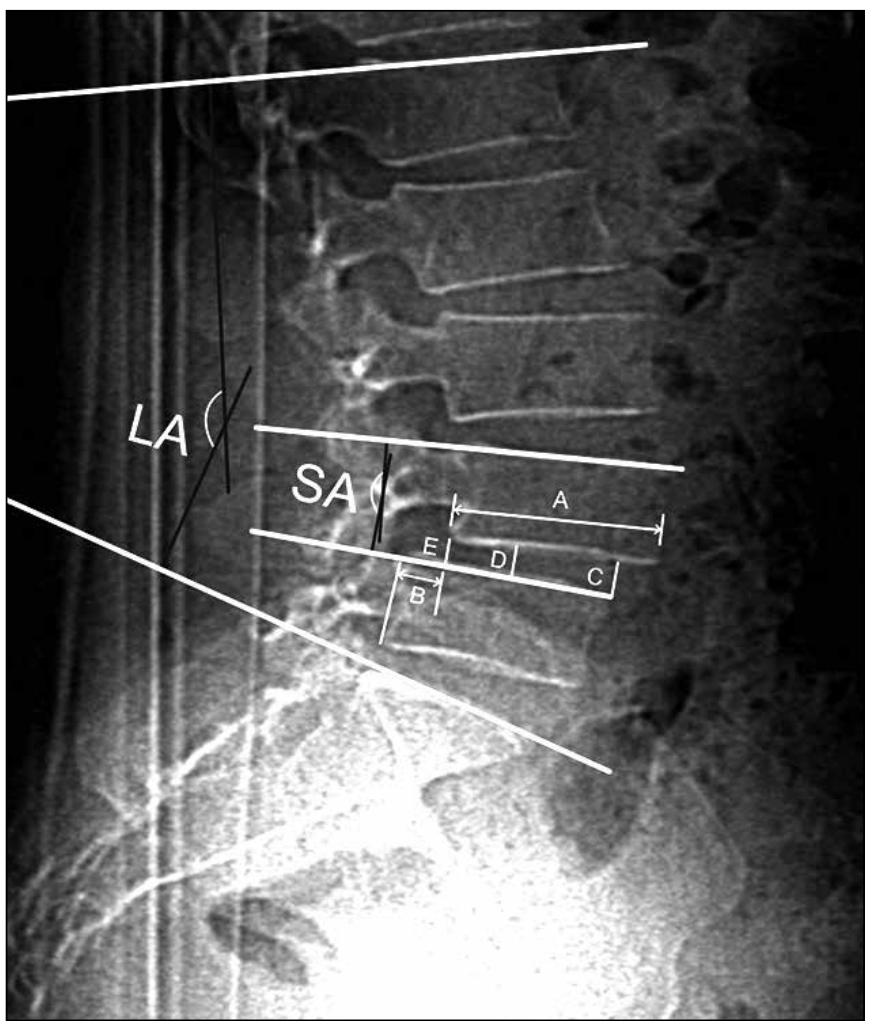

Figure 1: The ratio of vertebral slippage $=(B / A) X 100 \% ; A=T h e$ anteroposterior dimension of the slipped vertebral body, $\mathbf{B}=$ The distance between the posterior line of the vertebral body below the slipped vertebrae and the parallel line extending through a posterior rim of the slipped vertebrae; $\mathbf{I H}=(C+D+E) / 3 ; \mathbf{C}=$ Height of anterior intervertebral space, $\mathbf{D}=$ Height of median intervertebral space, $\mathbf{E}=$ Height of posterior intervertebral space, $\mathbf{S A}=$ Between the superior end plate of the slipped vertebral body and the superior end plate of the vertebrae below the slipped vertebrae using the Cobb method, LA=Between the superior end plate of L1 to the inferior end plate of L5 using the Cobb method. postoperatively than preoperatively $(10.3 \pm 1.6 \mathrm{~mm}$ vs. $7.7 \pm 1.9$ $\mathrm{mm}, \mathrm{p}<0.001)$ at the operated segment. There was no statistical difference in the ratio of vertebral slippage and $\mathrm{IH}$ postoperatively and at last follow-up ( $p>0.01)$. The SA slight increased postoperatively than did preoperatively $(13.5 \pm 5.7$ vs. 11.7 \pm 5.8 ), with insignificant statistical difference, and the LA exhibited modest decline, but with insignificant statistical difference (Table I). All patients were confirmed to achieve bony fusion. Results in a patient with a one-level IS at L4-L5 was shown in Figure 3A-H.

\section{Clinical Outcomes}

The VAS score at the last follow-up was significantly decreased as compared to that preoperatively $(2.4 \pm 0.5$ vs. $7.7 \pm 0.6, p<0.001)$, as was also true of ODI score (49.6 \pm 1.6 vs. $10.5 \pm 1.3, p<0.001$, Table II), whereas the corresponding JOA scores at the last follow-up were significantly increased versus those preoperatively $(10.8 \pm 1.3$ vs. $26.6 \pm 1.0, p<0.001$, Table II). The subjective evaluation outcomes at the last follow-up were encouraging, with "excellent" in 30 patients (93.75\%) and "good" in 2 patients $(6.25 \%)$.

\section{DISCUSSION}

IS is common in adolescents and adults, with L5-S1 and L4-L5 levels being the most frequently involved segments $(18,43)$. IS is defined as the forward slippage of a vertebra resulting from a defect in the pars interarticularis, with an incidence ranging from 6 to $8.2 \%$ and higher in males than in females (18). For the initial onset of IS in adolescents, conservative therapy is recommended, whereas surgery is considered in the case of conservative therapy failure, aggravation or progression of the condition $(9,12,26,40)$. Surgical options include a primary decompression without fusion, or combination with interbody fusion. In prior years, a decompression procedure alone was the most frequent surgical regimen in a selected patient group (3), but due to

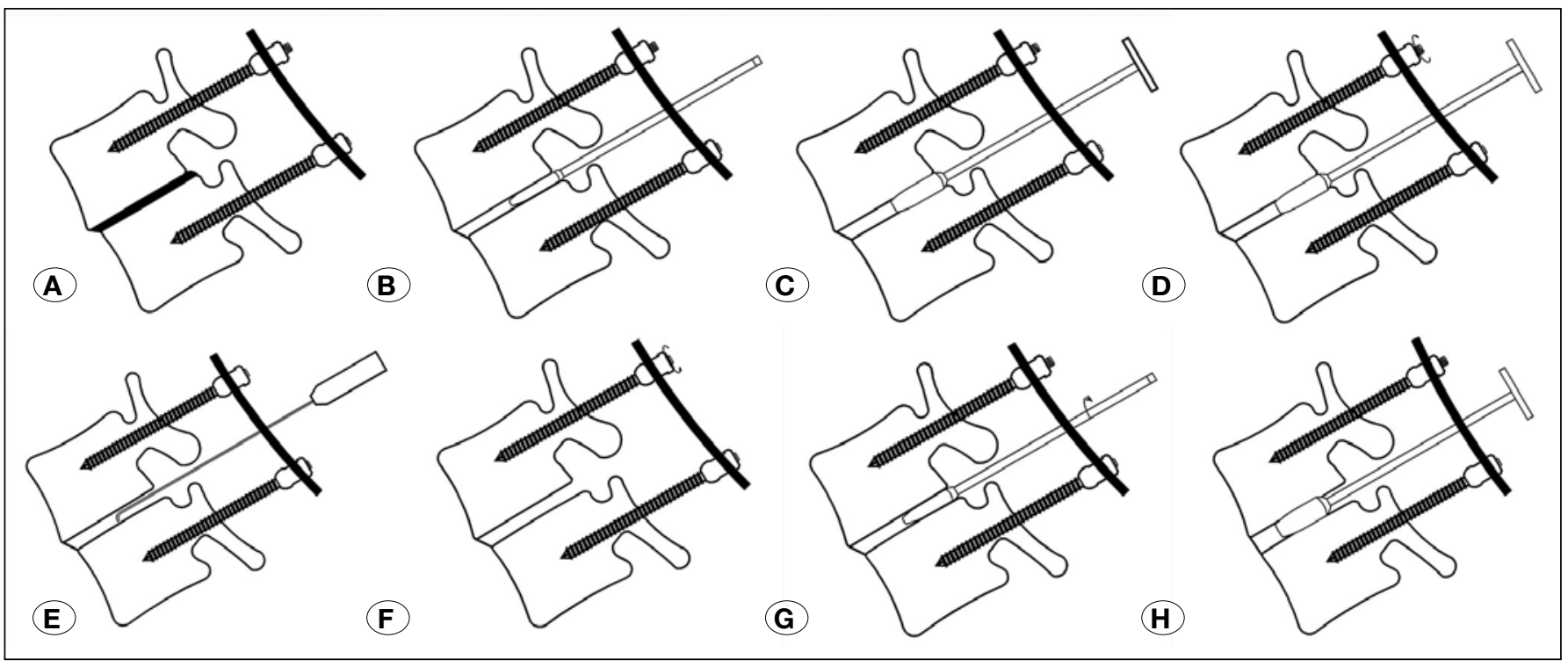

Figure 2: Reduction technique of the isthmic spondylolisthesis. 
Table I: Radiological Results in all the Patients

\begin{tabular}{lccc}
\hline & Preoperative & Postoperative & Last follow-up \\
\hline Slippage ratio (\%) & $17.8 \pm 4.3$ & $5.3 \pm 2.4^{*}$ & $5.4 \pm 2.5^{*}$ \\
\hline $\mathbf{I H}(\mathbf{m m})$ & $7.7 \pm 1.9$ & $10.3 \pm 1.6^{*}$ & $10.2 \pm 1.5^{*}$ \\
\hline SA $\left(^{\circ}\right)$ & $11.7 \pm 5.8$ & $13.5 \pm 5.7$ & $13.2 \pm 5.3$ \\
\hline LA $\left(^{\circ}\right)$ & $49.1 \pm 13.9$ & $48.3 \pm 9.4$ & $47.7 \pm 8.8$ \\
\hline
\end{tabular}

${ }^{*} p<0.05$ compared with preoperative values. IH: Intervertebral space height, SA: Lordotic angle of the treated segment, LA: Lumbar lordotic angle.

Table II: Clinical Results in Patients

\begin{tabular}{lccc}
\hline & VAS scores & ODI scores & JOA scores \\
\hline Preoperative & $7.7 \pm 0.6$ & $49.6 \pm 1.6$ & $10.8 \pm 1.3$ \\
\hline Last follow-up & $2.4 \pm 0.5^{*}$ & $10.5 \pm 1.3^{*}$ & $26.6 \pm 1.0^{\star}$ \\
\hline
\end{tabular}

${ }^{*} p<0.05$ compared with preoperative values. VAS: Visual analogue scale, ODI: Oswestry disability index, JOA: Japanese Orthopaedic Association.

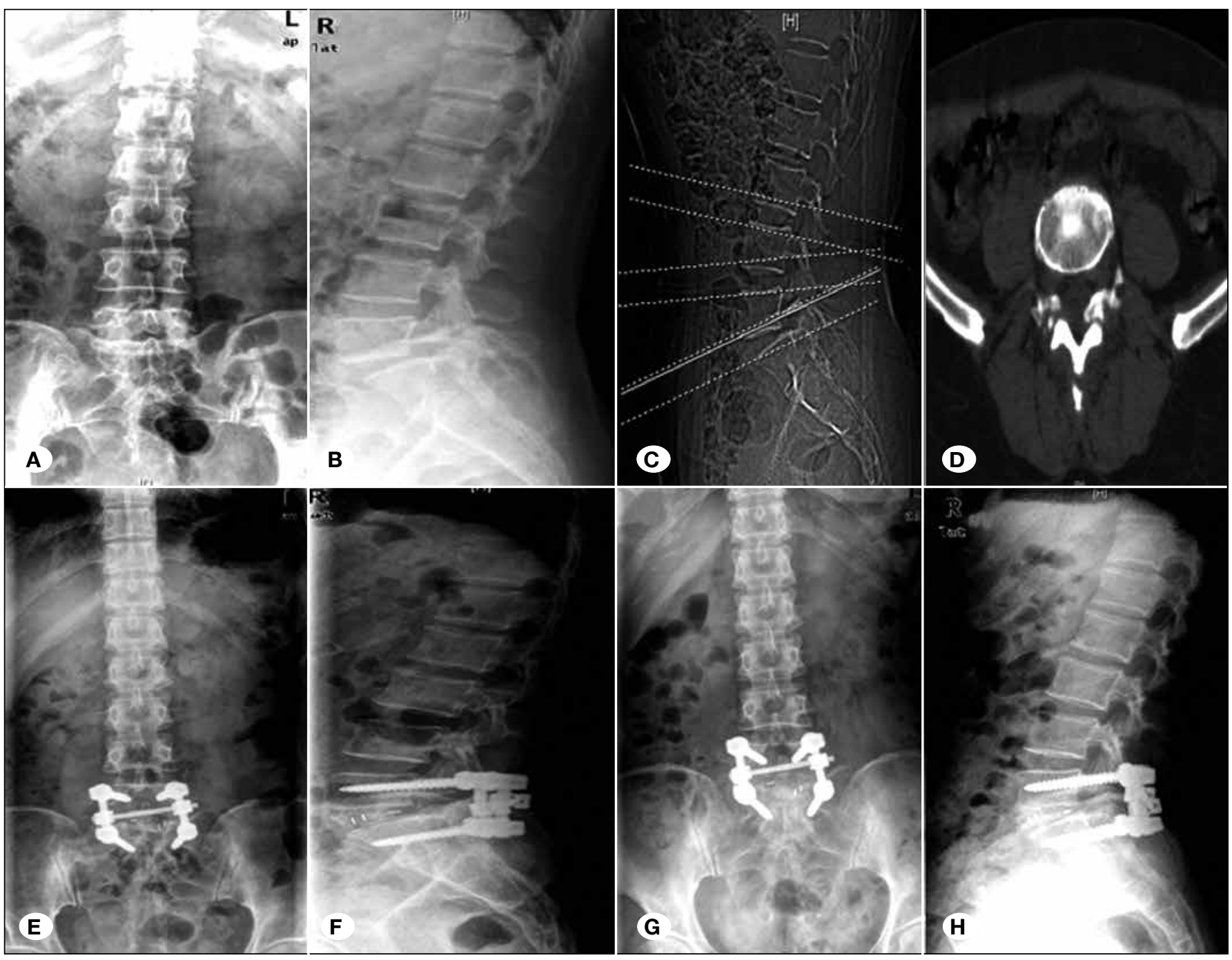

Figure 3: A,B) Preoperative anteroposterior and lateral view of a 44-year old female patient with L5 grade 1 spondylolisthesis. C,D) Preoperative lateral CT scanogram and axial CT scan, E,F) Anteroposterior and lateral films at first postoperative day, G,H) Anteroposterior and lateral films at the last follow-up. 
the inherent instability of IS per se, decompression alone is no longer recommended (5). Currently, the most popular procedure is lumbar fusion combined with decompression, which yields better results than decompression alone (38). Types of lumbar fusion included posterolateral lumbar fusion (PLF), anterior lumbar interbody fusion (ALIF), PLIF, and TLIF. However, no consensus has been reached as to what kind of surgery is the optimal and the decision of a decompression alone or combination with a lumbar fusion in any given patient.

Disputes also exist with respect to the feasibility and the extent of reduction of vertebral slippage. Fusion in situ used to be the prevailing surgical procedure in the treatment of mild spondylolisthesis, with good and safe long-term results $(21,33,42)$, and was identified superior to reduction for severe spondylolisthesis $(17,32)$. However, reconstruction of spinal balance has been widely accepted in the treatment of spinal disorders (37), since realignment of the spine and achievement of sagittal spine balance may prevent premature degeneration of adjacent level disc in the long run $(1,4,6,19,20,39)$ and reduce the incidence of peri-operative complications (34). Despite the lack of a consensus as to the criteria of optimal surgical approach and the potential risks of neurologic injury from instrumented slippage reduction, this approach is still practiced among many surgeons $(22,25)$. All the patients in our study underwent reduction, in which disc space was appropriately distracted and spontaneous slippage partially reduced without screw traction, with the screw tension and failure risks for osteosynthesis and reduction remarkably decreased.

Conventional TLIF technique is limited due to the insufficient manipulation dimensions for complete resection of nucleus pulposus and cartilaginous end plates, and thus we adopted a modified technique by temporary fixation of the distracted disc space to provide more procedural convenience, facilitating complete decompression of the intervertebral contents to promote vertebral reduction and bone fusion. Notably, we elaborated the criteria on the distraction of interbody space, i.e. normal tonus of the anterior wall of annulus fibrosus and anterior longitudinal ligament, or the height of segment concerned approximate to the mean height of superior and inferior intervertebral space by intraoperative radiography, which may greatly facilitate implementation and generalization.

Reduction of spondylolisthetic deformity can reportedly be achieved with an modified insert-and-rotate technique by means of diameter-ascending distractors, with the slippage percentage significantly reduced from the preoperative $27.9 \%$ to the postoperative $17.5 \%$, local lordosis significantly increased from $11.5^{\circ}$ preoperatively to $15.7^{\circ}$ postoperatively as well as the significant elevation of disc height from 14.3 $\mathrm{mm}$ preoperatively to $25.7 \mathrm{~mm}$ postoperatively (22). In the present study, the slippage percentage was significantly corrected from the preoperative $17.8 \%$ to the postoperative $5.3 \%$ and accordingly, the $\mathrm{IH}$ of the operated segment was significantly increased from $7.7 \mathrm{~mm}$ to $10.3 \mathrm{~mm}$ and the SA was modestly increased from $11.7^{\circ}$ to $13.5^{\circ}$ with insignificant difference, whereas the LA was decreased from $49.1^{\circ}$ to $48.3^{\circ}$. Our result was supported by prior studies in which the $\mathrm{IH}$ and
SA postoperatively were improved in patients undergoing TLIF for IS. However, a slight decrease in postoperative LA was paradoxically observed in our study. We attributed this discrepancy to the distinction between conventional pedicle screw reduction and our insert-and-rotate technique, which involved the trial spacer without screw elevation. Consequently, the tension of pedicle screw system was diminished, with the risks of failures in osteosynthesis and reduction greatly obviated, which was supported by the report of Pan et al. (31).

From the subjective evaluation questionnaires of 32 patients in our study, 'excellent' was in 30 patients and 'good' in 2 patients, with no patients scoring fair or worse at the final follow-up. In parallel, the clinical outcomes including VAS, ODI and JOA scores postoperatively and at the last followup exhibited significant improvements, with superior results $(29,36)$. Bone fusion was achieved in all patients, with signs and symptoms significantly ameliorated.

PLIF can be associated with nerve injury, dural tear and epidural scarring, resulting from excess medial retraction of the dura mater during cage implantation $(2,14,41)$. As an alternative to PLIF, TLIF adopts a posterior approach to the spine via the distal lateral portion of the vertebral foramen, which reduces the PLIF-associated risks of neurological injuries $(11,45)$. In our study, the incidence of post-operative iatrogenic neuroradicular dysfunction was $0 \%$, which was consistent with the results of previous reports $(23,35)$ and authenticated the efficacy of TLIF with low risk of neural injury. Both the wound infection and the re-operation rate was $0 \%$.

All the patients achieved spontaneous partial reduction of slippage by the trial spacer without any necessity of screw elevation, with signs and symptoms significantly ameliorated or even disappearing. For the follow-up of over 2-year duration, the patients exhibited significantly reduced slippage percentage and increased $\mathrm{IH}$, and modestly modified SA and LA. Despite the insignificant alterations of SA and LA in our study, our results were non-inferior to those with significant changes on grounds of our similar clinical outcomes $(24,28)$.

Our study was limited because of the relatively small sample size and short follow-up period. Large-scale multicenter prospective trials are required to recruit more patients to evaluate this approach.

\section{CONCLUSION}

The modified Jaslow technique combined with TLIF technique for the treatment of IS is advantageous for its greater safety, reliability, feasibility and popularity.

\section{- REFERENCES}

1. Akamaru T, Kawahara N, Tim Yoon S, Minamide A, Su Kim K, Tomita K, Hutton WC: Adjacent segment motion after a simulated lumbar fusion in different sagittal alignments: A biomechanical analysis. Spine 28(14):1560-1566, 2003

2. DiPaola CP, Molinari RW: Posterior lumbar interbody fusion. $J$ Am Acad Orthop Surg 16(3):130-139, 2008 
3. Epstein NE, Epstein JA, Carras R, Lavine LS: Degenerative spondylolisthesis with an intact neural arch: A review of 60 cases with an analysis of clinical findings and the development of surgical management. Neurosurgery 13(5):555-561, 1983

4. Floman $\mathrm{Y}$, Millgram MA, Ashkenazi E, Smorgick $\mathrm{Y}$, Rand N: Instrumented slip reduction and fusion for painful unstable isthmic spondylolisthesis in adults. J Spinal Disord Tech 21(7):477-483, 2008

5. Ghogawala Z, Benzel EC, Amin-Hanjani S, Barker FG 2nd, Harrington JF, Magge SN, Strugar J, Coumans JV, Borges LF: Prospective outcomes evaluation after decompression with or without instrumented fusion for lumbar stenosis and degenerative Grade I spondylolisthesis. J Neurosurg Spine 1(3):267-272, 2004

6. Goyal N, Wimberley DW, Hyatt A, Zeiller S, Vaccaro AR, Hilibrand AS, Albert TJ: Radiographic and clinical outcomes after instrumented reduction and transforaminal lumbar interbody fusion of mid and high-grade isthmic spondylolisthesis. J Spinal Disord Tech 22(5):321-327, 2009

7. Greenough CG, Peterson MD, Hadlow S, Fraser RD: Instrumented posterolateral lumbar fusion. Results and comparison with anterior interbody fusion. Spine 23(4):479486, 1998

8. Gruskay JA, Webb ML, Grauer JN: Methods of evaluating lumbar and cervical fusion. Spine J 14(3):531-539, 2014

9. Hammerberg KW: New concepts on the pathogenesis and classification of spondylolisthesis. Spine 30 Suppl 6:S4-11, 2005

10. Harrington PR, Tullos HS: Spondylolisthesis in children. Observations and surgical treatment. Clin Orthop Relat Res 79:75-84, 1971

11. Harris BM, Hilibrand AS, Savas PE, Pellegrino A, Vaccaro AR, Siegler S, Albert TJ: Transforaminal lumbar interbody fusion: The effect of various instrumentation techniques on the flexibility of the lumbar spine. Spine 29(4):E65-70, 2004

12. Herman MJ, Pizzutillo PD, Cavalier R: Spondylolysis and spondylolisthesis in the child and adolescent athlete. Orthop Clin North Am 34(3):461-467, 2003

13. Hoy K, Bunger C, Niederman B, Helmig P, Hansen ES, Li $H$, Andersen $T$ : Transforaminal lumbar interbody fusion (TLIF) versus posterolateral instrumented fusion (PLF) in degenerative lumbar disorders: A randomized clinical trial with 2-year follow-up. Eur Spine J 22(9):2022-2029, 2013

14. Humphreys SC, Hodges SD, Patwardhan AG, Eck JC, Murphy $\mathrm{RB}$, Covington LA: Comparison of posterior and transforaminal approaches to lumbar interbody fusion. Spine 26(5):567-571, 2001

15. Jacobs WC, Vreeling A, De Kleuver M: Fusion for low-grade adult isthmic spondylolisthesis: A systematic review of the literature. Eur Spine J 15(4):391-402, 2006

16. Jaslow IA: Intercorporal bone graft in spinal fusion after disc removal. Surg Gynecol Obstet 82:215-218, 1946

17. Johnson JR, Kirwan EO: The long-term results of fusion in situ for severe spondylolisthesis. J Bone Joint Surg Br 65(1):4346, 1983

18. Kalichman L, Kim DH, Li L, Guermazi A, Berkin V, Hunter DJ: Spondylolysis and spondylolisthesis: Prevalence and association with low back pain in the adult community-based population. Spine 34(2):199-205, 2009
19. Kanayama M, Cunningham BW, Sefter JC, Goldstein JA, Stewart G, Kaneda K, McAfee PC: Does spinal instrumentation influence the healing process of posterolateral spinal fusion? An in vivo animal model. Spine 24(11):1058-1065, 1999

20. Kawakami M, Tamaki T, Ando M, Yamada H, Hashizume $\mathrm{H}$, Yoshida M: Lumbar sagittal balance influences the clinical outcome after decompression and posterolateral spinal fusion for degenerative lumbar spondylolisthesis. Spine 27(1):59-64, 2002

21. Lamberg T, Remes V, Helenius I, Schlenzka D, Seitsalo S, Poussa M: Uninstrumented in situ fusion for high-grade childhood and adolescent isthmic spondylolisthesis: Longterm outcome. J Bone Joint Surg Am 89(3):512-518, 2007

22. Lian XF, Hou TS, Xu JG, Zeng BF, Zhao J, Liu XK, Yang EZ, Zhao C: Single segment of posterior lumbar interbody fusion for adult isthmic spondylolisthesis: Reduction or fusion in situ. Eur Spine J 23(1):172-179, 2014

23. Liu J, Deng H, Long X, Chen X, Xu R, Liu Z: A comparative study of perioperative complications between transforaminal versus posterior lumbar interbody fusion in degenerative lumbar spondylolisthesis. Eur Spine J 25(5):1575-1580, 2016

24. Liu ZD, Li XF, Qian L, Wu LM, Lao LF, Wang HT: Lever reduction using polyaxial screw and rod fixation system for the treatment of degenerative lumbar spondylolisthesis with spinal stenosis: Technique and clinical outcome. J Orthop Surg Res 10:29, 2015

25. Longo UG, Loppini M, Romeo G, Maffulli N, Denaro V: Evidence-based surgical management of spondylolisthesis: Reduction or arthrodesis in situ. J Bone Joint Surg Am 96(1):53-58, 2014

26. McNeely ML, Torrance G, Magee DJ: A systematic review of physiotherapy for spondylolysis and spondylolisthesis. Man Ther 8(2):80-91, 2003

27. Mehdian SH, Arun R: A new three-stage spinal shortening procedure for reduction of severe adolescent isthmic spondylolisthesis: A case series with medium- to long-term follow-up. Spine 36(11):E705-711, 2011

28. Musluman AM, Yilmaz A, Cansever T, Cavusoglu H, Colak I, Genc HA, Aydin Y: Posterior lumbar interbody fusion versus posterolateral fusion with instrumentation in the treatment of low-grade isthmic spondylolisthesis: Midterm clinical outcomes. J Neurosurg Spine 14(4):488-496, 2011

29. Ogilvie JW: Complications in spondylolisthesis surgery. Spine 30 Suppl 6:S97-101, 2005

30. Okuda S, Oda T, Miyauchi A, Haku T, Yamamoto T, Iwasaki $M$ : Surgical outcomes of posterior lumbar interbody fusion in elderly patients. J Bone Joint Surg Am 88(12):2714-2720, 2006

31. Pan J, Li L, Qian L, Zhou W, Tan J, Zou L, Yang M: Spontaneous slip reduction of low-grade isthmic spondylolisthesis following circumferential release via bilateral minimally invasive transforaminal lumbar interbody fusion: Technical note and short-term outcome. Spine 36(4):283-289, 2011

32. Poussa M, Remes V, Lamberg T, Tervahartiala P, Schlenzka D, Yrjonen T, Osterman K, Seitsalo S, Helenius I: Treatment of severe spondylolisthesis in adolescence with reduction or fusion in situ: Long-term clinical, radiologic, and functional outcome. Spine 31(5):583-590; discussion 591-592, 2006 
33. Poussa M, Schlenzka D, Seitsalo S, Ylikoski M, Hurri $\mathrm{H}$, Osterman K: Surgical treatment of severe isthmic spondylolisthesis in adolescents. Reduction or fusion in situ. Spine 18(7):894-901, 1993

34. Roussouly P, Nnadi C: Sagittal plane deformity: An overview of interpretation and management. Eur Spine J 19(11):18241836, 2010

35. Sakeb N, Ahsan K: Comparison of the early results of transforaminal lumbar interbody fusion and posterior lumbar interbody fusion in symptomatic lumbar instability. Indian $\mathrm{J}$ Orthop 47(3):255-263, 2013

36. Sears W: Posterior lumbar interbody fusion for lytic spondylolisthesis: Restoration of sagittal balance using insertand-rotate interbody spacers. Spine J 5(2):161-169, 2005

37. Sears W: Posterior lumbar interbody fusion for degenerative spondylolisthesis: Restoration of sagittal balance using insertand-rotate interbody spacers. Spine J 5(2):170-179, 2005

38. Shufflebarger HL, Geck MJ: High-grade isthmic dysplastic spondylolisthesis: Monosegmental surgical treatment. Spine 30 Suppl 6:S42-48, 2005

39. Steffee AD, Sitkowski DJ: Reduction and stabilization of grade IV spondylolisthesis. Clin Orthop and Relat Res 227:82-89, 1988
40. Steiner ME, Micheli LJ: Treatment of symptomatic spondylolysis and spondylolisthesis with the modified Boston brace. Spine 10(10):937-943, 1985

41. Talia AJ, Wong ML, Lau HC, Kaye AH: Comparison of the different surgical approaches for lumbar interbody fusion. $J$ Clin Neurosci 22(2):243-251, 2015

42. Thomsen K, Christensen FB, Eiskjaer SP, Hansen ES, Fruensgaard S, Bunger CE: 1997 Volvo Award winner in clinical studies. The effect of pedicle screw instrumentation on functional outcome and fusion rates in posterolateral lumbar spinal fusion: A prospective, randomized clinical study. Spine 22(24):2813-2822, 1997

43. Tsirikos Al, Garrido EG: Spondylolysis and spondylolisthesis in children and adolescents. J Bone Joint Surg Br 92(6):751759, 2010

44. Witoon $\mathrm{N}$, Tangviriyapaiboon $\mathrm{T}$ : Clinical and radiological outcomes of segmental spinal fusion in transforaminal lumbar interbody fusion with spinous process tricortical autograft. Asian Spine J 8(2):170-176, 2014

45. Xiao YX, Chen QX, Li FC: Unilateral transforaminal lumbar interbody fusion: A review of the technique, indications and graft materials. J Int Med Res 37(3):908-917, 2009 